Article

\title{
Conversion of Squid Pens to Chitosanases and Proteases via Paenibacillus sp. TKU042
}

\author{
Chien Thang Doan ${ }^{1,2}$, Thi Ngoc Tran ${ }^{1,2}$, Van Bon Nguyen 2 (D) Anh Dzung Nguyen ${ }^{3}$ and \\ San-Lang Wang ${ }^{1,4, * \text { iD }}$ \\ 1 Department of Chemistry, Tamkang University, New Taipei City 25137, Taiwan; \\ doanthng@gmail.com (C.T.D.); tranngoctnu@gmail.com (T.N.T.) \\ 2 Department of Science and Technology, Tay Nguyen University, Buon Ma Thuot City 630000, Vietnam; \\ bondhtn@gmail.com \\ 3 Institute of Biotechnology and Environment, Tay Nguyen University, Buon Ma Thuot City 630000, Vietnam; \\ nadzungtaynguyenuni@yahoo.com.vn \\ 4 Life Science Development Center, Tamkang University, New Taipei City 25137, Taiwan \\ * Correspondence: sabulo@mail.tku.edu.tw; Tel.: +886-2-2621-5656; Fax: +886-2-2620-9924
}

Received: 10 February 2018; Accepted: 6 March 2018; Published: 8 March 2018

\begin{abstract}
Chitosanases and proteases have received much attention due to their wide range of applications. Four kinds of chitinous materials, squid pens, shrimp heads, demineralized shrimp shells and demineralized crab shells, were used as the sole carbon and nitrogen $(\mathrm{C} / \mathrm{N})$ source to produce chitosanases, proteases and $\alpha$-glucosidase inhibitors $(\alpha \mathrm{GI})$ by four different strains of Paenibacillus. Chitosanase productivity was highest in the culture supernatants using squid pens as the sole $\mathrm{C} / \mathrm{N}$ source. The maximum chitosanase activity of fermented squid pens $(0.759 \mathrm{U} / \mathrm{mL})$ was compared to that of fermented shrimp heads $(0.397 \mathrm{U} / \mathrm{mL})$, demineralized shrimp shells $(0.201 \mathrm{U} / \mathrm{mL})$ and demineralized crab shells $(0.216 \mathrm{U} / \mathrm{mL})$. A squid pen concentration of $0.5 \%$ was suitable for chitosanase, protease and $\alpha$ GI production via Paenibacillus sp. TKU042. Multi-purification, including ethanol precipitation and column chromatography of Macro-Prep High S as well as Macro-Prep DEAE (diethylaminoethyl), led to the isolation of Paenibacillus sp. TKU042 chitosanase and protease with molecular weights of 70 and $35 \mathrm{kDa}$, respectively. For comparison, 16 chitinolytic bacteria, including strains of Paenibacillus, were investigated for the production of chitinase, exochitinase, chitosanase, protease and $\alpha \mathrm{GI}$ using two kinds of chitinous sources.
\end{abstract}

Keywords: chitin; chitosan; squid pens; chitosanase; protease; $\alpha$-glucosidase inhibitors; Paenibacillus

\section{Introduction}

Chitin is one of the most abundant renewable natural polymers, second only to cellulose. Chitin and its derivatives, such as chitosan and chitin/chitosan oligomers, possess great economic value because of their diverse biological activities and biotechnological applications. Among chitin-containing bioresources, crab shells, shrimp shells and squid pens have the highest chitin content $[1,2]$. These marine byproducts contain not only chitin, but proteins and mineral salts as well. Chemical treatments, using strong alkali and acids for deproteinization and demineralization, are traditionally used to prepare chitin and chitosan from crab shells, shrimp shells and squid pens [2-5]. However, these chemical procedures have several drawbacks, including the large amount of protein-containing wastewater produced due to the high alkali content [1]. The development of green techniques, such as the application of enzymes for chitin extraction, is gaining greater attention. The cost of using enzymes can be decreased by incorporating deproteinization via fermentation, which can be achieved by proteolytic microorganisms [1-6]. 
Chitin and chitosan have been widely used as $\mathrm{C} / \mathrm{N}$ (carbon/nitrogen) sources for the production of bacterial chitinolytic enzymes [1]. To reduce costs and recycle chitinous processing materials more efficiently, shrimp shells, crab shells and squid pens have been used as the sole $\mathrm{C} / \mathrm{N}$ sources for screening chitinolytic and proteolytic enzyme-producing bacteria [7-10]. Unlike chitin and chitosan, chitin-containing fishery byproducts show greater potential as $\mathrm{C} / \mathrm{N}$ sources since they can produce chitinolytic enzymes, proteases and other high-value-added bioactive materials [11-19].

Among chitin-containing fishery byproducts, squid pens contain the highest percentage of proteins and are most suitable for producing enzymes [7-11] and various bioactive compounds, such as antioxidants [13-15], $\alpha$-glucosidase inhibitors ( $\alpha$ GI) [16-18], biofertilizers [19,20], compounds with antitumor properties [13], biosurfactants [21], exopolysaccharides [21-23], insecticidal materials [24,25] and chitin, as well as chitin oligomers [20].

Many strains of Paenibacillus have applications in the agricultural, industrial and medical fields [26]. Recently, some strains of Paenibacillus were investigated for their ability to produce $\alpha$-glucosidase inhibitors [16-18], exopolysaccharides [21-23] and anti-inflammatory antioxidants [14] when squid pens were the sole $\mathrm{C} / \mathrm{N}$ source. However, few reports exist about chitinolytic and/or proteolytic enzymes from Paenibacillus, especially using squid pens. As such, there is interest in using squid pens to produce chitosanase and protease via fermentation with Paenibacillus.

In this study, four chitinous materials, including squid pen powder (SPP), demineralized shrimp shell powder (deSSP), shrimp head powder (SHP) and demineralized crab shell powder (deCSP), were used as the sole $\mathrm{C} / \mathrm{N}$ sources for chitosanase and protease production by Paenibacillus sp. TKU042 and three other Paenibacillus strains. Optimal culture conditions and enzyme purification were investigated as well as the characterization of the Paenibacillus sp. TKU042 chitosanases and proteases. In previous studies, Paenibacillus sp. TKU042 has been reported to produce $\alpha$-glucosidase inhibitors in a deCSP-containing medium. Therefore, a comparison of the $\alpha$-glucosidase inhibitors produced by the four Paenibacillus strains was also performed.

\section{Results and Discussion}

\subsection{Screening of Chitinous Materials as Sole C/N for Chitosanase Production}

To explore the production of chitosanase and protease via Paenibacillus, four strains (TKU029, TKU032, TKU037, and TKU042) were incubated in a liquid medium containing 1\% (w/v) of different chitinous materials, which were used as the sole C/N source. These included SPP, deSSP, SHP and deCSP. The Paenibacillus strains exhibited highest chitosanase activity in the culture supernatants of medium containing SPP, with a productivity of $0.928 \mathrm{U} / \mathrm{mL}$ for TKU042, $0.714 \mathrm{U} / \mathrm{mL}$ for TKU032, $0.529 \mathrm{U} / \mathrm{mL}$ for TK037 and $0.440 \mathrm{U} / \mathrm{mL}$ for TKU029. The incubation time to achieve maximum chitosanase activity was shortest for TKU042 (2 days) compared to the other strains (3 days). After two days of fermentation, Paenibacillus sp. TKU042 showed the highest chitosanase activity $(0.928 \mathrm{U} / \mathrm{mL})$ in medium containing SPP, compared to SHP $(0.397 \mathrm{U} / \mathrm{mL})$, deSSP $(0.201 \mathrm{U} / \mathrm{mL})$ and $\operatorname{deCSP}$ (0.216 U/mL).

Recently, Paenibacillus sp. TKU042 was suggested as a potential bacterium for the food and medical industries, thanks to its ability to produce $\alpha$ GI with high efficiency via fermentation in a commercial medium (nutrient broth), and especially on chitinous materials [16-18]. Therefore, this study not only screened the optimal chitinous materials $(1 \% w / v)$ for producing chitosanase and protease, but also examined the production of $\alpha$-glucosidase inhibitors. SPP was best for producing chitosanase $(0.928 \mathrm{U} / \mathrm{mL})$, while protease activity reached its maximum value $(0.622 \mathrm{U} / \mathrm{mL})$ in SHP-containing medium after 2 days of fermentation; higher $\alpha$ GI activity was found in both deSSP $(182.55 \mathrm{U} / \mathrm{mL})$ and deCSP (182.09 U/mL) mediums (after 2 days of fermentation). These results were consistent with the research of Nguyen et al. [17], which showed that Paenibacillus sp. TKU042 produced higher $\alpha$ GI activity in deCSP- and deSSP-containing media. 
With its high ratio of proteins and low ratio of mineral salts, SPP is suitable for producing chitosanase via many bacterial strains $[1,2,10,15]$. In this study, SPP was also found to be the best $\mathrm{C} / \mathrm{N}$ source for chitosanase production by Paenibacillus sp. TKU042.

\subsection{Effect of SPP Concentration on Chitosanase, Protease and $\alpha$ GI Production}

According to the above results, SPP was considered the best $\mathrm{C} / \mathrm{N}$ source for chitosanase production by Paenibacillus sp. TKU042. To determine the optimal SPP concentration for chitosanase, protease and $\alpha \mathrm{GI}$ production, the basal medium $\left(0.1 \% \mathrm{~K}_{2} \mathrm{HPO}_{4}, 0.05 \% \mathrm{MgSO}_{4} \cdot 7 \mathrm{H}_{2} \mathrm{O}\right)$ was supplemented with different concentrations $(0.5 \%, 1 \%, 1.5 \%, 2 \%)$. As shown in Figure $1 \mathrm{~A}$, the highest chitosanase activity was found for 1.5\% SPP $(1.120 \mathrm{U} / \mathrm{mL}, 2$ days $)$ and $2 \%$ SPP $(1.162 \mathrm{U} / \mathrm{mL}, 2$ days $)$. Conversely, a lower concentration of SPP $(0.5 \%)$ gave better results for the production of protease $(0.876 \mathrm{U} / \mathrm{mL}, 2$ days) and $\alpha \mathrm{GI}(106.66 \mathrm{U} / \mathrm{mL}, 3$ days). Overall, higher concentrations ( $2 \%$ or $1.5 \%)$ of SPP are suitable for chitosanase production, but not for protease or $\alpha \mathrm{GI}$. Due to there being no significant differences in chitosanase activity between $1.5 \%(1.120 \mathrm{U} / \mathrm{mL})$ and $2.0 \% \mathrm{SPP}(1.162 \mathrm{U} / \mathrm{mL})$, $1.5 \%$ was chosen as the most suitable concentration for chitosanase production.
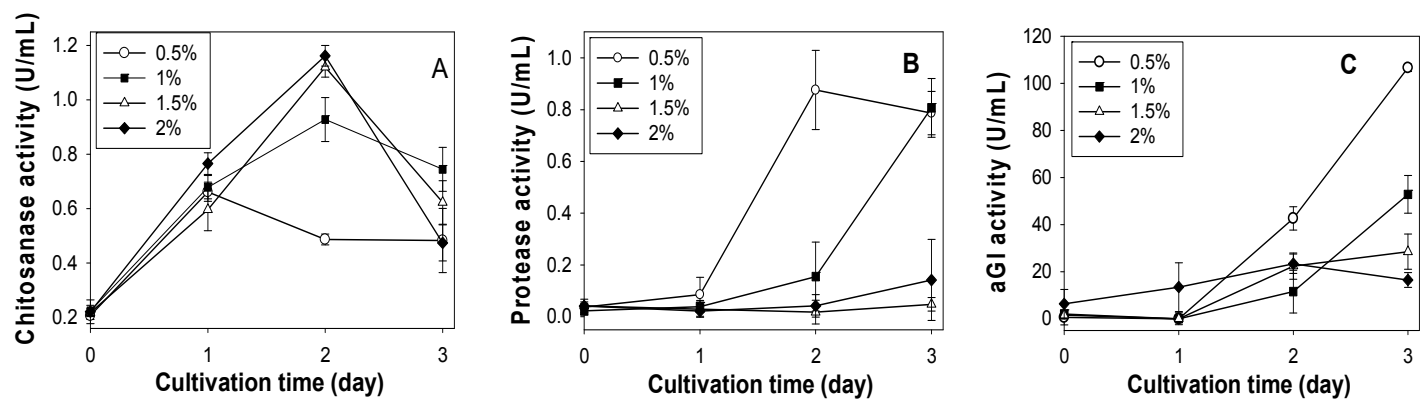

Figure 1. Effect of SPP concentration on the production of chitosanase, protease and $\alpha$ GI by Paenibacillus sp. TKU042. (A) chitosanase activity; (B) protease activity; (C) $\alpha$ GI activity. Paenibacillus sp. TKU042 has been reported to produce higher $\alpha \mathrm{GI}$ activity in deCSP than any of the other three chitinous materials (SPP, deSSP and SHP) when used as the sole C/N source [17]. To examine whether the production of chitosanase $(1.5 \% \mathrm{SPP})$ and protease $(0.5 \% \mathrm{SPP})$ may be enhanced by a combination of deCSP and SPP, $1 \%$ deCSP was added to the medium. As seen in Figure 2, the combination of SPP with deCSP enhanced the production of protease (Figure 2B), but not chitosanase (Figure 2A) or $\alpha \mathrm{GI}$ (Figure 2C).
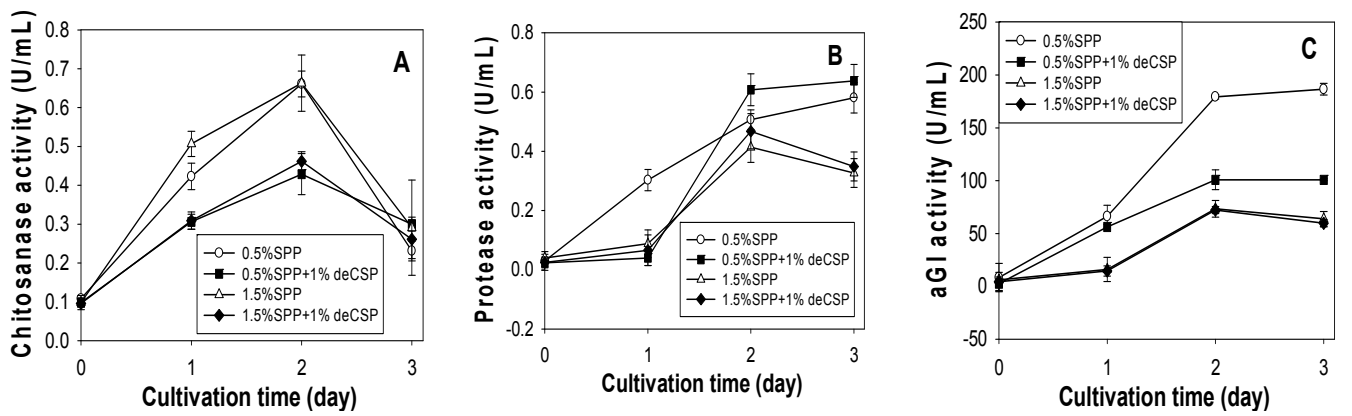

Figure 2. Effect of combining SPP with deCSP on the production of chitosanase, protease and $\alpha \mathrm{GI}$ by Paenibacillus sp. TKU042. (A) chitosanase activity; (B) protease activity; (C) $\alpha \mathrm{GI}$ activity.

\subsection{Production of Chitosanase, Protease and $\alpha$ GI from SPP and deCSP by Different Bacteria}

To make a wide comparison between the production of chitosanase, protease and $\alpha \mathrm{GI}$ by different Paenibacillus strains, 12 chitinolytic bacteria strains isolated from Taiwanese soils were tested. SPP (suitable for chitosanase production) and deCSP (suitable for $\alpha$ GI production) 
were used as the sole $\mathrm{C} / \mathrm{N}$ sources. Since the substrates used for analyzing exochitinase ( $p$-nitrophenyl- $N$-acetyl- $\beta$-D-glucosaminide) and chitinase (colloidal chitin) were similar to that for chitosanase (water-soluble chitosan), the activities of exochitinase and chitinase were also examined and compared.

As shown in Table 1, the highest protease activity was found in four Paenibacillus strains: TKU032 (1.366 U/mL), TKU042 (1.257 U/mL), TKU037 (1.203 U/mL) and TKU029 (0.925 U/mL). For $\alpha \mathrm{GI}$ production, Paenibacillus strains TKU042 (185.45 U/mL), TKU037 (180.77 U/mL) and TKU 032 $(178.38 \mathrm{U} / \mathrm{mL})$ again produced the highest results; TKU029 $(62.90 \mathrm{U} / \mathrm{mL})$ was the only exception. For chitinase production, Paenibacillus sp. TKU042 $(0.182 \mathrm{U} / \mathrm{mL})$ showed higher production than TKU037 $(0.135 \mathrm{U} / \mathrm{mL})$, TKU029 $(0.118 \mathrm{U} / \mathrm{mL})$ or TKU032 $(0.072 \mathrm{U} / \mathrm{mL})$. Serratia ureilytica TKU013 produced the most exochitinase $(0.276 \mathrm{U} / \mathrm{mL})$ and chitinase $(0.266 \mathrm{U} / \mathrm{mL})$. No significant differences were found between the 16 strains for chitosanase production. Among the four Paenibacillus strains, the highest chitosanase activity $(0.122 \mathrm{U} / \mathrm{mL})$ was found in Paenibacillus macerans TKU029. Based on these results, deCSP was a better $\mathrm{C} / \mathrm{N}$ source for the production of $\alpha \mathrm{GI}$ and protease by Paenibacillus, especially Paenibacillus sp. TKU042, which generated higher chitinase, chitosanase, protease and $\alpha \mathrm{GI}$ activities.

Table 1. Comparison of chitinolytic enzyme, protease and $\alpha$ GI production by various bacteria using deCSP as $\mathrm{C} / \mathrm{N}$ source.

\begin{tabular}{cccccc}
\hline \multirow{2}{*}{ Strain } & \multicolumn{5}{c}{ Activity (U/mL) } \\
\cline { 2 - 6 } & Exochitinase & Chitinase & Chitosanase & Protease & aGI \\
\hline Paenibacillus macerans TKU029 & - & $0.118+0.027$ & $0.122+0.035$ & $0.925+0.032$ & $62.90+6.755$ \\
P. mucilaginosus TKU032 & - & $0.072+0.016$ & $0.086+0.021$ & $1.366+0.045$ & $178.38+10.312$ \\
Paenibacillus sp. TKU037 & - & $0.135+0.018$ & $0.069+0.019$ & $1.203+0.041$ & $180.77+11.620$ \\
Paenibacillus sp. TKU042 & - & $0.182+0.036$ & $0.088+0.015$ & $1.257+0.038$ & $185.45+3.085$ \\
Bacillus licheniformis TKU004 & - & - & $0.089+0.022$ & $0.121+0.023$ & $91.29+8.692$ \\
Bacillus subtilis TKU007 & - & $0.163+0.023$ & - & $0.178+0.011$ & $96.06+7.008$ \\
Lactobacillus paracasei TKU010 & - & $0.216+0.033$ & - & $0.113+0.009$ & - \\
Serratia marcescens TKU011 & - & $0.201+0.029$ & $0.149+0.021$ & $0.115+0.012$ & $73.63+4.090$ \\
Serratia ureilytica TKU013 & $0.276+0.012$ & $0.266+0.018$ & $0.099+0.017$ & $0.202+0.024$ & $64.52+3.474$ \\
Pseudomonas tamsuii TKU015 & - & $0.193+0.030$ & $0.105+0.013$ & $0.103+0.008$ & $51.54+4.627$ \\
Serratia sp. TKU016 & $0.152+0.021$ & $0.104+0.012$ & $0.110+0.022$ & $0.101+0.007$ & 68.962 .292 \\
Serratia sp. TKU020 & $0.121+0.016$ & $0.102+0.015$ & $0.151+0.013$ & $0.099+0.009$ & $73.63+6.420$ \\
Bacillus cereus TKU028 & - & $0.127+0.018$ & $0.111+0.018$ & $0.776+0.053$ & $68.72+5.143$ \\
Bacillus mycoildes TKU038 & - & - & $0.101+0.017$ & $0.463+0.036$ & $111.67+1.036$ \\
Bacillus mycoildes TKU040 & - & $0.191+0.020$ & - & - & - \\
Rhizobium sp.TKU041 & - & - & - & - & - \\
\hline
\end{tabular}

deCSP was used at the sole $\mathrm{C} / \mathrm{N}$ source with a concentration of $1 \%(w / v)$. Culture conditions were set at $37^{\circ} \mathrm{C}$, $150 \mathrm{rpm}$ shaking speed, $100 / 250 \mathrm{~mL}$ (volume of medium/flask) for two days. The cultures of fermented deCSP were obtained and centrifuged at $12,000 \times g$ for 20 min to collect the culture supernatants. (-) expressed activity lower than $0.1 \mathrm{U} / \mathrm{mL}$ and $10 \mathrm{U} / \mathrm{mL}$ for exochitinase and $\alpha \mathrm{GI}$, respectively.

When $1 \%$ SPP was used as the sole C/N source (Table 2), Paenibacillus strains showed higher chitosanase and $\alpha \mathrm{GI}$ activity than the other genus strains. Highest chitosanase activity was found in Paenibacillus sp. TKU042 (0.928 U/mL), followed by Paenibacillus macerans TKU029 $(0.857 \mathrm{U} / \mathrm{mL})$. $\alpha$ GI production was highest in Paenibacillus strains TKU037 $(175.80 \mathrm{U} / \mathrm{mL})$, TKU032 $(175.40 \mathrm{U} / \mathrm{mL})$, TKU042 $(88.30 \mathrm{U} / \mathrm{mL})$ and TKU029 $(60.13 \mathrm{U} / \mathrm{mL})$. Serratia ureilytica TKU013 generated the highest protease $(0.910 \mathrm{U} / \mathrm{mL})$ and exochitinase $(11.545 \mathrm{U} / \mathrm{mL})$ activity.

Paenibacillus strains TKU042, TKU037, TKU032 and TKU029 demonstrated higher $\alpha$ GI activity in deCSP (Table 1) than SPP (Table 2). These results were consistent with previous reports [17]. This study also found two strains of Bacillus (TKU004 and TKU038) with the potential to produce $\alpha$ GI. B. licheniformis TKU004 produced $174.59 \mathrm{U} / \mathrm{mL} \alpha \mathrm{GI}$ in SPP (Table 2) and B. mycoildes TKU038 produced $111.67 \mathrm{U} / \mathrm{mL} \alpha \mathrm{GI}$ in deCSP (Table 1). Similar results were also found in Bacillus subtilis B2 [27] and B. subtilis MORI [28], which were cultured for $\alpha$ GI production in okara and soybean extracts, respectively. 
Table 2. Comparison of chitinolytic enzyme, protease and $\alpha \mathrm{GI}$ production by various bacteria using $\mathrm{SPP}$ as $\mathrm{C} / \mathrm{N}$ source.

\begin{tabular}{cccccc}
\hline Strain & \multicolumn{5}{c}{ Activity (U/mL) } \\
\cline { 2 - 6 } & Exochitinase & Chitinase & Chitosanase & Protease & aGI \\
\hline Paenibacillus macerans TKU029 & - & $0.376+0.026$ & $0.857+0.015$ & $0.135 \pm 0.011$ & $60.13 \pm 6.844$ \\
P. mucilaginosus TKU032 & - & $0.101+0.017$ & $0.155+0.016$ & $0.193 \pm 0.005$ & $175.40 \pm 0.606$ \\
Paenibacillus sp. TKU037 & - & $0.105+0.018$ & $0.247+0.014$ & $0.222 \pm 0.004$ & $175.80 \pm 0.851$ \\
Paenibacillus sp.TKU042 & - & $0.185+0.019$ & $0.928+0.014$ & $0.199+0.005$ & $88.30 \pm 4.502$ \\
Bacillus licheniformis TKU004 & $1.211+0.017$ & $0.074+0.017$ & $0.120+0.014$ & $0.707+0.020$ & $174.59 \pm 4.295$ \\
Bacillus subtilis TKU007 & - & $0.118+0.017$ & $0.314+0.017$ & $0.219+0.005$ & $58.64 \pm 7.368$ \\
Lactobacillus paracasei TKU010 & - & - & $0.166+0.015$ & $0.090+0.010$ & - \\
Serratia marcescens TKU011 & $8.039+0.296$ & $0.177+0.018$ & $0.150+0.013$ & $0.477+0.010$ & - \\
Serratia ureilytica TKU013 & $11.545+0.431$ & $0.319+0.019$ & $0.112+0.013$ & $0.910+0.031$ & $52.60 \pm 8.418$ \\
Pseudomonas tamsuii TKU015 & - & $0.105+0.015$ & $0.056+0.013$ & $0.113+0.009$ & - \\
Serratia sp. TKU016 & - & $0.111+0.018$ & $0.302+0.012$ & $0.370+0.012$ & - \\
Serratia sp. TKU020 & $9.327+0.325$ & $0.201+0.018$ & $0.118+0.014$ & $0.478+0.021$ & $52.49 \pm 0.778$ \\
Bacillus cereus TKU028 & - & $0.223+0.018$ & $0.520+0.015$ & $0.153+0.007$ & $68.64 \pm 3.972$ \\
Bacillus mycoildes TKU038 & - & $0.332+0.019$ & $0.611+0.016$ & $0.240+0.004$ & $71.46 \pm 3.635$ \\
Bacillus mycoildes TKU040 & - & $0.350+0.016$ & $0.165+0.013$ & $0.083+0.011$ & - \\
Rhizobium sp.TKU041 & - & - & - & $0.198+0.012$ & - \\
\hline
\end{tabular}

SPP was used at the sole $\mathrm{C} / \mathrm{N}$ source with a concentration of $1 \%(w / v)$. Culture conditions were set at $37^{\circ} \mathrm{C}$, $150 \mathrm{rpm}$ shaking speed, $100 / 250 \mathrm{~mL}$ (volume of medium/flask) for two days. The cultures of fermented deCSP were obtained and centrifuged at $12,000 \times g$ for 20 min to collect the culture supernatants. (-) expressed activity lower than $0.1 \mathrm{U} / \mathrm{mL}$ and $10 \mathrm{U} / \mathrm{mL}$ for exochitinase and $\alpha \mathrm{GI}$, respectively.

Recently, many strains of Paenibacillus have been found to produce exopolysaccharides when cultured in medium containing squid pens [22,23,29] or carbohydrates, such as sucrose [30]. Interestingly, a strain of Bacillus licheniformis (OSTK95) also produced exopolysaccharides in glucose-containing medium [31]. In fact, Paenibacillus was originally included within the Bacillus genus and was then reclassified as a separate genus in 1993 [32]. With results similar to Paenibacillus, the fact that Bacillus licheniformis TKU004 produces $\alpha$ GI (Table 2) and B. licheniformis OSTK95 produces exopolysaccharides [31] suggests that Bacillus strains, especially B. licheniformis, could potentially be developed for the production of $\alpha \mathrm{GI}$ and exopolysaccharides.

In this study, all bacterial strains were isolated using chitin- and protein-containing media as the sole $\mathrm{C} / \mathrm{N}$ sources. It was assumed that to obtain nutrition, the bacteria would produce chitinolytic enzymes or proteases by hydrolyzing the chitin or protein in the medium. For this reason, the chitinolytic enzymes, including exochitinase and chitinase, were also studied. As shown in Tables 1 and 2, most of the tested strains showed chitinase activity on both SPP and deCSP. Among all the bacteria, Paenibacillus sp. TKU029 produced the highest chitinase activity on SPP $(0.376 \mathrm{U} / \mathrm{mL})$.

Extracellular chitinases were divided into two types: exochitinase or endochitinase. While endochitinase activity was defined as random cleavage at internal points in the chitin chain, exochitinase activity was defined as a progressive action starting at the non-reducing end of chitin, with the release of chitobiose or $\mathrm{N}$-acetylglucosamine units [9]. In this study, chitinase was produced by most of the bacteria, but exochitinase was only found in four strains: Bacillus licheniformis TKU004, Serratia marcescens TKU011, Serratia ureilytica TKU013 and Serratia sp. TKU020. None of the Paenibacillus strains produced exochitinase (Tables 1 and 2). Therefore, Paenibacillus TKU042 chitinase is classified as an endochitinase.

\subsection{Purification and Characterization of Chitosanase and Protease}

Unlike $\alpha \mathrm{GI}$, there are few reports of chitinolytic enzymes and proteases being produced by Paenibacillus species. Chitosanase produced by Paenibacillus ehimensis NRRL B-23118 has been studied, but purification was not performed [33]. To compare the different chitinases and proteases produced by Paenibacillus sp. TKU042 against other reported strains, the chitosanase and protease of Paenibacillus sp. TKU042 were purified from the culture supernatant by a series of steps. The enzymes were 
eluted by Macro-Prep High S chromatography with a linear gradient of $0-1 \mathrm{M} \mathrm{NaCl}$, using the same buffer (Figure 3). The eluted peak fractions were pooled for further purification. After two rounds of chromatography (data not shown), approximately $0.52 \mathrm{mg}$ of chitosanase and $0.20 \mathrm{mg}$ of protease were obtained (Tables 3 and 4). The specific activity and recovery yields of chitosanase were $3.09 \mathrm{U} / \mathrm{mg}$ and $3.09 \%$, respectively (Table 3), while for protease they were $38.19 \mathrm{U} / \mathrm{mg}$ and $8.70 \%$, respectively (Table 4).

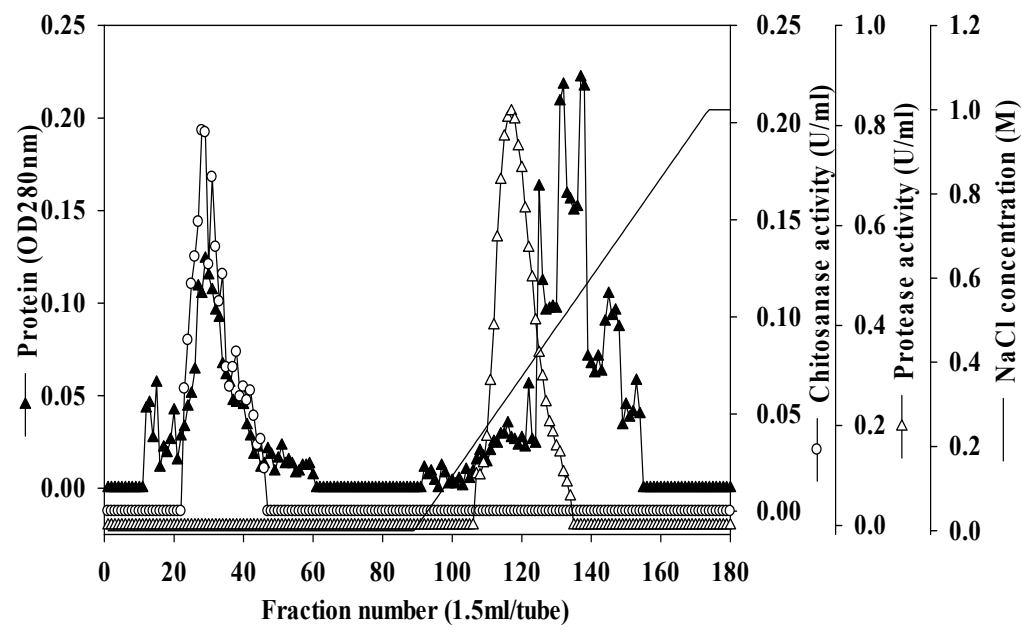

Figure 3. Elution profile of chitosanase and protease on Macro-Prep High S.

Table 3. Purification of the chitosanase from Paenibacillus sp. TKU042.

\begin{tabular}{cccccc}
\hline Step & $\begin{array}{c}\text { Total Protein } \\
(\mathbf{m g})\end{array}$ & $\begin{array}{c}\text { Total } \\
\text { Activity (U) }\end{array}$ & $\begin{array}{c}\text { Specific Activity } \\
\text { (U/mg) }\end{array}$ & $\begin{array}{c}\text { Recovery } \\
\text { (\%) }\end{array}$ & $\begin{array}{c}\text { Purification } \\
\text { (Fold) }\end{array}$ \\
\hline Cultural supernatant & 211.43 & 53.03 & 0.25 & $100.00 \%$ & 1.00 \\
Ethanol precipitation & 56.95 & 26.81 & 0.47 & $50.56 \%$ & 1.88 \\
Macro-Prep High S & 4.59 & 4.62 & 1.01 & $8.71 \%$ & 4.01 \\
Macro-Prep DEAE & 0.52 & 1.64 & 3.14 & $3.09 \%$ & 12.51 \\
\hline
\end{tabular}

Paenibacillus sp. TKU042 was cultured in $100 \mathrm{~mL}$ of liquid medium in a $250 \mathrm{~mL}$ Erlenmeyer flask containing $1 \% \mathrm{SPP}$, $0.1 \% \mathrm{~K}_{2} \mathrm{HPO}_{4}$ and $0.05 \% \mathrm{MgSO}_{4} \cdot 7 \mathrm{H}_{2} \mathrm{O}$ in a shaking incubator for 2 days at $37^{\circ} \mathrm{C}$. Protein content was estimated by a previously described method [10] using bovine serum albumin as the standard.

Table 4. Purification of the protease from Paenibacillus sp. TKU042.

\begin{tabular}{cccccc}
\hline Step & $\begin{array}{c}\text { Total Protein } \\
(\mathbf{m g})\end{array}$ & $\begin{array}{c}\text { Total } \\
\text { Activity (U) }\end{array}$ & $\begin{array}{c}\text { Specific Activity } \\
\text { (U/mg) }\end{array}$ & $\begin{array}{c}\text { Recovery } \\
\text { (\%) }\end{array}$ & $\begin{array}{c}\text { Purification } \\
\text { (Fold) }\end{array}$ \\
\hline Cultural supernatant & 211.43 & 86.90 & 0.41 & $100.00 \%$ & 1.00 \\
Ethanol precipitation & 56.95 & 60.35 & 1.06 & $69.45 \%$ & 2.58 \\
Macro-Prep High S & 2.72 & 17.10 & 6.29 & $19.68 \%$ & 15.30 \\
Sephacryl 200 & 0.20 & 7.56 & 38.19 & $8.70 \%$ & 92.91 \\
\hline
\end{tabular}

Paenibacillus sp. TKU042 was cultured in $100 \mathrm{~mL}$ of liquid medium in a $250 \mathrm{~mL}$ Erlenmeyer flask containing $1 \% \mathrm{SPP}$, $0.1 \% \mathrm{~K}_{2} \mathrm{HPO}_{4}$ and $0.05 \% \mathrm{MgSO}_{4} \cdot 7 \mathrm{H}_{2} \mathrm{O}$ in a shaking incubator for 2 days at $37^{\circ} \mathrm{C}$. Protein content was estimated by a previously described method [10] using bovine serum albumin as the standard.

The molecular masses of the TKU042 chitosanase and protease were approximately $70 \mathrm{kDa}$ and $35 \mathrm{kDa}$, as determined by the SDS-PAGE (sodium dodecyl sulfate polyacrylamide gel electrophoresis) (Figure 4). The molecular weight of TKU042 chitosanase $(70 \mathrm{kDa})$ was larger than that of $B$. subtilis KH1 (28 kDa) [34], B. ehimensis EAG1 (31 kDa) [35], B. subtilis IMR-NK1 (36 kDa) [36], B. licheniformis A10 (40.5 KDa) [37], B. megaterium p1 (22, 39.5, $43 \mathrm{kDa})$ [38], B. cereus S1 (45 kDa) [39], Bacillus sp. KCTC0377BP (45 kDa) [40], Bacillus sp. P16 (45 kDa) [41], B. mycoides TKU038 (48 kDa) [10], Bacillus 
sp. MET1299 (52 kDa) [42] and Paenibacillus sp. 1794 (40 kDa) [43]; only Paenibacillus fukuinensis D2 (67 kDa) had a similar weight [44]. Meanwhile, Paenibacillus sp. TKU042 protease (35 kDa) fell within the recorded range (19.95-67.61 kDa) from other strains of Paenibacillus [45,46] and Bacillus [47-49].

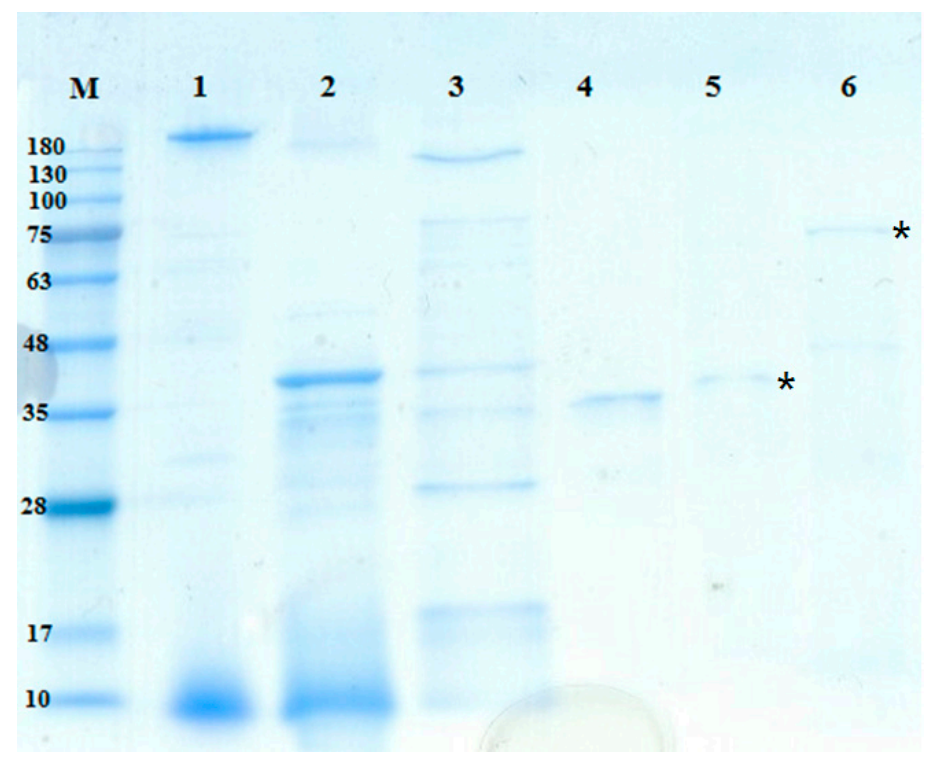

Figure 4. SDS-PAGE analysis of the protease and chitosanase produced by TKU042. Lanes: M. molecular markers; 1 . cultural supernatant; 2 . crude enzyme after precipitation of ethanol; 3 . adsorbed chitosanase after Macro-Prep High S Chromatography; 4. adsorbed protease after Macro-Prep High S Chromatography; 5. purified protease after Sephacryl 200 Chromatography; 6. purified chitosanase after Macro-Prep DEAE Cartridge Chromatography; *, the purified enzymes.

\section{Materials and Methods}

\subsection{Materials}

Squid pens, crab shells and shrimp shells were obtained from Shin-Ma Frozen Food Co. (I-Lan, Taiwan) [17]. Shrimp head powder was obtained from Fwu-Sow Industry (Taichun, Taiwan). Demineralized crab shells and demineralized shrimp shells were preparative via acid treatment [17]. Saccharomyces cerevisiae $\alpha$-glucosidase, the substrates for determining enzyme activities (water-soluble chitosan, chitin (from shrimp shells) and $p$-nitrophenyl- $N$-acetyl- $\beta$-D-glucosaminide), the reference compounds ( $p$-nitrophenol, tyrosine, $N$-acetylglucosamine and glucosamine) and the reagents (3,5-dinitrosalicylic acid and Folin-Ciocalteu) were all purchased from Sigma-Aldrich Corp. (Singapore). Sephacryl S200 was purchased from GE healthcare UK Ltd. (Little Chalfont, Buckinghamshire, England, UK). Macro-prep DEAE and Macro-Prep High S were obtained from Bio-Rad (Hercules, CA, USA). All other reagents were of the highest grade available.

\subsection{Measurement of Enzyme Activities}

\subsubsection{Chitosanase Activity}

The measurement of chitosanase activity was performed according to a previously described method [10], with modifications. Water-soluble chitosan (1\% in $50 \mathrm{mM}$ phosphate buffer) was used as the substrate. The reaction was performed with $0.2 \mathrm{~mL}$ substrate and $0.2 \mathrm{~mL}$ enzyme solution and kept at $37^{\circ} \mathrm{C}$ for $60 \mathrm{~min}$. The amount of reducing sugar produced in the supernatant was determined by DNS reagent, with glucosamine as the reference compound. One unit of enzyme activity was defined as the amount of enzyme that produced $1 \mu \mathrm{mol}$ of reducing sugar per min [10]. 


\subsubsection{Protease Activity}

To measure protease activity, the enzyme solution $(0.1 \mathrm{~mL})$ was mixed with $0.1 \mathrm{~mL}$ substrate $(1 \%$ casein in $50 \mathrm{mM}$ phosphate buffer) and incubated for $60 \mathrm{~min}$ at $37^{\circ} \mathrm{C}$. The reaction was stopped by adding $0.6 \mathrm{~mL}$ TCA solution (5\%). The reaction mixture was then measured as per the methods of Todd, with tyrosine as the reference compound [19]. One unit of protease activity was defined as the amount of enzyme required to release $1 \mu \mathrm{mol}$ of tyrosine per min.

\subsubsection{Chitinase Activity}

Measurement of chitinase activity was performed according to the methods described above for chitosanase, with slight modifications. Instead of water-soluble chitosan, colloidal chitin $(1 \%$ in $50 \mathrm{mM}$ phosphate buffer) was used as the substrate and $\mathrm{N}$-acetylglucosamine was used as the reference compound instead of $\mathrm{N}$-glucosamine [7].

\subsubsection{Exochitinase Activity}

Exochitinase activity was determined as per the previously described methods [7], with modifications. The culture supernatant $(50 \mu \mathrm{L})$ was mixed with $100 \mu \mathrm{L}$ of $p$-nitrophenyl- $N$-acetyl- $\beta$ D-glucosaminide solution $(1 \mathrm{~g} / \mathrm{L})$ and $500 \mu \mathrm{L}$ of $50 \mathrm{mM}$ sodium acetate buffer $(\mathrm{pH} 4.6)$, then incubated at $37^{\circ} \mathrm{C}$ for $30 \mathrm{~min}$. The color of $p$-nitrophenol (pNP) appeared once $325 \mu \mathrm{L}$ of sodium carbonate (50 mM, pH 10.7) was added to the mixture solution. The final solution was measured at $410 \mathrm{~nm}$. pNP was used as the reference compound. One unit of enzyme activity was defined as the amount of enzyme that produced $1 \mu \mathrm{M}$ of pNP per min.

\subsection{Measurement of Alpha Glucosidase Inhibitor}

To measure $\alpha \mathrm{GI}$ activity, the inhibitor solution $(10 \mu \mathrm{L})$ was mixed with $10 \mu \mathrm{L}$ of $\alpha$-glucosidase solution $(1 \mathrm{U})$ and $0.1 \mathrm{~mL}$ phosphate buffer $(100 \mathrm{mM})$, then kept at $37^{\circ} \mathrm{C}$ for $30 \mathrm{~min}$ [17]. $10 \mu \mathrm{L}$ of substrate $p$-nitrophenyl glucopyranoside (pNPG) was then added to the mixture before incubation at $37^{\circ} \mathrm{C}$ for $30 \mathrm{~min}$. The reaction was stopped by adding $0.13 \mathrm{~mL} \mathrm{Na} \mathrm{CO}_{3}$ solution $(1 \mathrm{M})$. The final mixture solution was measured at $410 \mathrm{~nm}$. The inhibition was calculated using the following formula,

$$
\text { Inhibition }(\%)=(\mathrm{A}-\mathrm{B}) / \mathrm{A} \times 100 \text {, }
$$

where $\mathrm{A}$ is the absorbance of the reaction blank at $410 \mathrm{~nm}$ (no inhibitor/sample), and $\mathrm{B}$ is the absorbance of the reaction at $410 \mathrm{~nm}$ in the presence of the inhibitor/sample. The concentration of an inhibitor that could inhibit $50 \%$ of enzymatic activity under assay conditions was defined as the $\mathrm{IC}_{50}$ value.

\subsection{Screening of Chitinous Materials as Sole C/N for Enzyme Activity}

Various kinds of chitin-containing materials, such as demineralized crab shell powder (deCSP), squid pen powder (SPP), shrimp head powder (SHP) and demineralized shrimp shell powder (deSSP) $(w / v)$ were used as the sole sources of $\mathrm{C} / \mathrm{N}$ at a concentration of $1 \%$. Four Paenibacillus strains were grown in $100 \mathrm{~mL}$ of liquid medium in $250 \mathrm{~mL}$ Erlenmeyer flasks containing $1 \%$ of each chitinous material, $0.1 \% \mathrm{~K}_{2} \mathrm{HPO}_{4}$ and $0.05 \% \mathrm{MgSO}_{4} \cdot 7 \mathrm{H}_{2} \mathrm{O}$. One $\mathrm{mL}$ of the seed culture was transferred into $100 \mathrm{~mL}$ of the medium and incubated for 3 days at $37^{\circ} \mathrm{C}$ on a shaking incubator (150 rpm). Every $24 \mathrm{~h}$, the culture broth was centrifuged $\left(12,000 \times g\right.$ at $4{ }^{\circ} \mathrm{C}$ for $\left.20 \mathrm{~min}\right)$ and the supernatant was used for further measurements.

\subsection{Effect of SPP Concentration on Enzymes and $\alpha$ GI Activity}

Paenibacillus sp. TKU042 was grown in a $250 \mathrm{~mL}$ Erlenmeyer flask with $100 \mathrm{~mL}$ of basal medium $\left(0.1 \% \mathrm{~K}_{2} \mathrm{HPO}_{4}\right.$, and $\left.0.05 \% \mathrm{MgSO}_{4} \cdot 7 \mathrm{H}_{2} \mathrm{O}\right)$ and a range of SPP concentrations $(0.5-2 \%)$ at $37{ }^{\circ} \mathrm{C}$ on a shaking incubator (150 rpm). For subsequent experiments, the optimal SPP concentration was mixed 
with $1 \%$ deCSP, and the mixture of chitinous material and basal medium was cultured under similar incubation conditions. Every $24 \mathrm{~h}$, the culture broth was centrifuged $\left(12,000 \times g\right.$ at $4{ }^{\circ} \mathrm{C}$ for $\left.20 \mathrm{~min}\right)$, and the supernatant was used for further measurements.

\subsection{Production of Enzymes and $\alpha$ GI from SPP and deCSP Using Different Bacteria}

Sixteen chitolytic bacterial strains were grown on two kinds of chitinous materials (SPP and deCSP). The incubation supernatants from the 4th day were used to measure exochitinase, chitinase, chitosanase, protease and $\alpha \mathrm{GI}$.

\subsection{Purification of Chitosanase and Protease}

$300 \mathrm{~mL}$ of cold ethanol $\left(-20^{\circ} \mathrm{C}\right)$ was added to $100 \mathrm{~mL}$ of culture supernatant and kept at $4{ }^{\circ} \mathrm{C}$ overnight for protein precipitation. The precipitate was collected by centrifugation at $12,000 \times g$ for $30 \mathrm{~min}$ and then dissolved in a small amount of $20 \mathrm{mM}$ Tris buffer $(\mathrm{pH} 7)$ and dialyzed against the buffer. The resulting crude enzyme was loaded onto a Macro-Prep High $S$ column that had been equilibrated with $20 \mathrm{mM}$ Tris buffer. A gradient of $\mathrm{NaCl}(0-1 \mathrm{M})$ in the same buffer was applied to the eluted enzymes. The enzyme solutions were then chromatographed on a Macro-prep DEAE column or on a Sephacryl S200 column $(1 \mathrm{~cm} \times 100 \mathrm{~cm})$. The molecular masses of the enzymes were determined using the SDS-PAGE methods.

\section{Conclusions}

Paenibacillus produces a variety of biofertilizers, antimicrobials, enzymes and exopolysaccharides with applications in agriculture, medicine, process manufacturing and bioremediation, some of which have already been commercialized [26]. Further study will reveal other means by which Paenibacillus can contribute to health and sustainable processes. In this study, the use of squid pens as the sole $\mathrm{C} / \mathrm{N}$ source gave the best results for chitosanase production by Paenibacillus sp. TKU042. The molecular weight of the purified TKU042 chitosanase $(70 \mathrm{kDa})$ was higher than the other Paenibacillus strains. Among the sixteen tested chitinolytic bacteria, Paenibacillus sp. TKU042 has the best potential to produce chitinolytic enzymes, protease and $\alpha$-glucosidase inhibitors using squid pens as the sole $\mathrm{C} / \mathrm{N}$ source.

Acknowledgments: This work was supported in part by a grant from the Ministry of Sciences and Technology, Taiwan (MOST 106-2320-B-032-001-MY3).

Author Contributions: S.-L.W. conceived and designed the study; C.T.D. performed the study; S.-L.W. contributed reagents/materials/analysis tools; S.-L.W., C.T.D., T.N.T., V.B.N.; and A.D.N. analyzed the data; C.T.D. and S.-L.W. wrote the paper.

Conflicts of Interest: The authors declare no conflict of interest.

\section{References}

1. Wang, S.L.; Liang, T. Microbial reclamation of squid pens and shrimp shells. Res. Chem. Intermed. 2017, 43, 3445-3462. [CrossRef]

2. Wang, S.L. Microbial reclamation of squid pen. Biocatal. Agric. Biotechnol. 2012, 1, 177-180. [CrossRef]

3. Kaur, S.; Dhillon, G.S. Recent trends in biological extraction of chitin from marine shell wastes: A review. Crit. Rev. Biotechnol. 2015, 35, 44-61. [CrossRef] [PubMed]

4. Younes, I.; Rinaudo, M. Chitin and chitosan preparation from marine sources. Structure, properties and applications. Mar. Drugs 2015, 13, 1133-1174. [CrossRef] [PubMed]

5. Younes, I.; Hajji, S.; Rinaudo, M.; Chaabouni, M.; Jellouli, K.; Nasri, M. Optimization of proteins and minerals removal from shrimp shells to produce highly acetylated chitin. Int. J. Biol. Macromol. 2016, 84, $246-253$. [CrossRef] [PubMed]

6. Ghorbel-Bellaaj, O.; Jellouli, K.; Younes, I.; Manni, L.; Ouled Salem, M.; Nasri, M. A solvent-stable metalloprotease produced by Pseudomonas aeruginosa A2 grown on shrimp shell waste and its application in chitin extraction. Appl. Biochem. Biotechnol. 2011, 164, 410-425. [CrossRef] [PubMed] 
7. Liang, T.W.; Chen, Y.Y.; Pan, P.S.; Wang, S.L. Purification of chitinase/chitosanase from Bacillus cereus and discovery of an enzyme inhibitor. Int. J. Biol. Macromol. 2014, 63, 8-14. [CrossRef] [PubMed]

8. Liang, T.W.; Lo, B.C.; Wang, S.L. Chitinolytic bacteria-assisted conversion of squid pen and its effect on dyes and adsorption. Mar. Drugs 2015, 13, 4576-4593. [CrossRef] [PubMed]

9. Wang, C.L.; Su, J.W.; Liang, T.W.; Nguyen, A.D.; Wang, S.L. Production, purification and characterization of a chitosanase from Bacillus cereus. Res. Chem. Intermed. 2014, 40, 2237-2248. [CrossRef]

10. Liang, T.W.; Chen, W.T.; Lin, Z.H.; Kuo, Y.H.; Nguyen, A.D.; Pan, P.S.; Wang, S.L. An amphiprotic novel chitosanase from Bacillus mycoides and its application in the production of chitooligomers with their antioxidant and anti-inflammatory evaluation. Int. J. Mol. Sci. 2016, 17, 1302. [CrossRef] [PubMed]

11. Liang, T.W.; Jen, S.N.; Nguyen, A.D.; Wang, S.L. Application of chitinous materials in production and purification of a poly (L-lactic acid) depolymerase from Pseudomonas tamsuii TKU015. Polymers 2016, 8, 98. [CrossRef]

12. Wang, S.L.; Chen, S.J.; Liang, T.W.; Lin, Y.D. A novel nattokinase produced by Pseudomonas sp. TKU015 using shrimp shells as substrate. Process Biochem. 2009, 44, 70-76. [CrossRef]

13. Kuo, Y.H.; Liang, T.W.; Liu, K.C.; Hsu, Y.W.; Hsu, H.; Wang, S.L. Isolation and identification of a novel antioxidant with antitumor activity from Serratia ureilytica using squid pen as fermentation substrate. Mar. Biotechnol. 2011, 13, 451-461. [CrossRef] [PubMed]

14. Wang, S.L.; Li, H.T.; Zhang, L.J.; Lin, Z.H.; Kuo, Y.H. Conversion of squid pen to homogentisic acid via Paenibacillus sp. TKU036 and the antioxidant and anti-inflammatory activities of homogentisic acid. Mar. Drugs 2016, 14, 183. [CrossRef] [PubMed]

15. Wang, S.L.; Wu, P.C.; Liang, T.W. Utilization of squid pen for the efficient production of chitosanase and antioxidants through prolonged autoclave treatment. Carbohydr. Res. 2009, 244, 979-984. [CrossRef] [PubMed]

16. Nguyen, V.B.; Nguyen, A.D.; Wang, S.L. Utilization of fishery processing by product squid pens for Paenibacillus sp. fermentation on producing potent $\alpha$-glucosidase inhibitors. Mar. Drugs 2017, 15, 274. [CrossRef] [PubMed]

17. Nguyen, V.B.; Wang, S.L. Reclamation of marine chitinous materials for the production of $\alpha$-glucosidase inhibitors via microbial conversion. Mar. Drugs 2017, 15, 350. [CrossRef] [PubMed]

18. Nguyen, V.B.; Wang, S.L. New novel $\alpha$-glucosidase inhibitors produced by microbial conversion. Process Biochem. 2017, 65, 228-232. [CrossRef]

19. Wang, S.L.; Huang, T.Y.; Wang, C.Y.; Liang, T.W.; Yen, Y.H.; Sakata, Y. Bioconversion of squid pen by Lactobacillus paracasei subsp paracasei TKU010 for the production of proteases and lettuce enhancing biofertilizers. Bioresour. Technol. 2008, 99, 5436-5443. [CrossRef] [PubMed]

20. Wang, S.L.; Hsu, W.H.; Liang, T.W. Conversion of squid pen by Pseudomonas aeruginosa K-187 fermentation for the production of $N$-acetyl chitooligosaccharides and biofertilizers. Carbohydr. Res. 2010, 345, 880-885. [CrossRef] [PubMed]

21. Liang, T.W.; Wu, C.C.; Cheng, W.T.; Chen, Y.C.; Wang, C.L.; Wang, I.L.; Wang, S.L. Exopolysaccharides and antimicrobial biosurfactants produced by Paenibacillus macerans TKU029. Appl. Biochem. Biotechnol. 2014, 172, 933-950. [CrossRef] [PubMed]

22. Liang, T.W.; Tseng, S.C.; Wang, S.L. Production and characterization of antioxidant properties of exopolysaccharides from Paenibacillus mucilaginosus TKU032. Mar. Drugs 2016, 14, 40. [CrossRef] [PubMed]

23. Liang, T.W.; Wang, S.L. Recent advances in exopolysaccharides from Paenibacillus spp.: Production, isolation, structure, and bioactivities. Mar. Drugs 2015, 13, 1847-1863. [CrossRef] [PubMed]

24. Wang, S.L.; Wang, C.Y.; Yen, Y.H.; Liang, T.W.; Chen, S.Y.; Chen, C.H. Enhanced production of insecticidal prodigiosin from Serratia marcescens TKU011 in media containing squid pen. Process Biochem. 2012, 47, 1684-1690. [CrossRef]

25. Hsu, C.H.; Nguyen, A.D.; Chen, Y.W.; Wang, S.L. Tyrosinase inhibitors and insecticidal materials produced by Burkholderia cepacia using squid pen as the sole carbon and nitrogen source. Res. Chem. Intermed. 2014, 40, 2249-2258. [CrossRef]

26. Grady, E.N.; MacDonald, J.; Liu, L.; Richman, A.; Yuan, Z.C. Current knowledge and perspectives of Paenibacillus: A review. Microb. Cell Fact. 2016, 15, 203. [CrossRef] [PubMed] 
27. Zhu, Y.P.; Yamaki, K.; Yoshihashi, T.; Ohnishi, K.M.; Li, X.T.; Cheng, Y.Q.; Mori, Y.; Li, L.T. Purification and identification of 1-deoxynojirimycin (DNJ) in okara fermented by Bacillus subtilis $\mathrm{B} 2$ from Chinese traditional food (meitaoza). J. Agric. Food Chem. 2010, 58, 4097-4103. [CrossRef] [PubMed]

28. Nam, H.; Jung, H.; Karuppasamy, S.; Park, Y.S.; Cho, Y.S.; Lee, J.Y.; Seong, S.; Suh, J.G. Anti-diabetic effect of the soybean extract fermented by Bacillus subtilis MORI in $d b / d b$ mice. Food Sci. Biotechnol. 2012, 21, 1669-1676. [CrossRef]

29. Wang, C.L.; Huang, T.H.; Liang, T.W.; Wang, S.L. Production and characterization of exopolysaccharides and antioxidant from Paenibacillus sp. TKU023. New Biotechnol. 2011, 28, 559-565. [CrossRef] [PubMed]

30. Liu, J.; Luo, J.; Ye, H.; Sun, Y.; Lu, Z.; Zeng, X. Production, characterization and antioxidant activities in vitro of exopolysaccharides from endophytic bacterium Paenibacillus polymyxa EJS-3. Carbohydr. Polym. 2009, 78, 275-281. [CrossRef]

31. Fang, Y.; Liu, S.; Lu, M.; Jiao, Y.; Wang, S. A novel method for promoting antioxidant exopolysaccharides production of Bacillus licheniformis. Carbohydr. Polym. 2013, 92, 1172-1176. [CrossRef] [PubMed]

32. Ash, C.; Priest, F.G.; Collins, M.D. Molecular identification of rRNA group 3 bacilli (Ash, Farrow, Wallbanks and Collins) using a PCR probe test. Proposal for the creation of a new genus Paenibacillus. Antonie Van Leewenhoek 1993, 64, 253-260. [CrossRef]

33. Pagnoncelli, M.G.B.; de Araújo1, N.K.; da Silva, N.M.P.; de Assis, C.F.; Rodrigues, S.; de Macedo, G.B. Chitosanase production by Paenibacillus ehimensis and its application for chitosan hydrolysis. Braz. Arch. Biol. Technol. 2010, 53, 1461-1468. [CrossRef]

34. Omumasaba, C.A.; Yoshida, N.; Sekiguchi, Y.; Kariya, K.; Ogawa, K. Purification and some properties of a novel chitosanase from Bacillus subtilis KH1. J. Gen. Appl. Microbiol. 2000, 46, 19-27. [CrossRef] [PubMed]

35. Akiyama, K.; Fujita, T.; Kuroshima, K.; Sakane, T.; Yokota, A.; Takata, R. Purification and gene cloning of a chitosanase from Bacillus ehimensis EAG1. J. Biosci. Bioeng. 1999, 87, 383-385. [CrossRef]

36. Chiang, C.L.; Chang, C.T.; Sung, H.Y. Purification and properties of chitosanase from a mutant of Bacillus subtilis IMR-NK1. Enzyme Microb. Technol. 2003, 32, 260-267. [CrossRef]

37. Yilmaz, B.; Baltaci, M.O.; Sisecioglu, M.; Adiguzel, A. Thermotolerant alkaline protease enzyme from Bacillus licheniformis A10: Purification, characterization, effects of surfactants and organic solvents. J. Enzyme Inhib. Med. Chem. 2016, 31, 1241-1247. [CrossRef] [PubMed]

38. Pelletier, A.; Sygusch, J. Purification and characterization of three chitosanase activities from Bacillus megaterium P1. Appl. Environ. Microbiol. 1990, 56, 844-848. [PubMed]

39. Kurakake, M.; You, S.; Nakagawa, K.; Sugihara, M.; Komaki, T. Properties of chitosanase from Bacillus cereus S1. Curr. Microbiol. 2000, 40, 6-9. [CrossRef] [PubMed]

40. Choi, Y.J.; Kim, E.J.; Piao, Z.; Yun, Y.C.; Shin, Y.C. Purification and characterization of chitosanase from Bacillus sp. strain KCTC 0377BP and its application for the production of chitosan oligosaccharides. Appl. Environ. Microbiol. 2004, 70, 4522-4531. [CrossRef] [PubMed]

41. Jo, Y.Y.; Jo, K.J.; Jin, Y.L.; Kim, K.Y.; Shin, J.H.; Kim, Y.W.; Park, R.D. Characterization and Kinetics of 45 kDa Chitosanase from Bacillus sp. P16. Biosci. Biotechnol. Biochem. 2003, 67, 1875-1882. [CrossRef] [PubMed]

42. Kim, P.I.; Kang, T.H.; Chung, K.J.; Kim, I.S.; Chung, K.C. Purification of a constitutive chitosanase produced by Bacillus sp. MET 1299 with cloning and expression of the gene. FEMS Microbiol. Lett. 2004, 240, 31-39. [CrossRef] [PubMed]

43. Zitouni, M.; Fortin, M.; Scheerle, R.K.; Letzel, T.; Matteau, D.; Rodrigue, S.; Brzezinski, R. Biochemical and molecular characterization of a thermostable chitosanase produced by the strain Paenibacillus sp. 1794 newly isolated from compost. Appl. Microbiol. Biotechnol. 2013, 97, 5801-5813. [CrossRef] [PubMed]

44. Kimoto, H.; Kusaoke, H.; Yamamoto, I.; Fujii, Y. Biochemical and genetic properties of Paenibacillus glycosyl hydrolase having chitosanase activity and discoidin domain. J. Biol. Chem. 2002, 17, 14695-14702. [CrossRef] [PubMed]

45. Rai, S.K.; Roy, J.K.; Mukherjee, A.K. Characterisation of a detergent-stable alkaline protease from a novel thermophilic strain Paenibacillus tezpurensis sp. nov. AS-S24-II. Appl. Microbiol. Biotechnol. 2010, 85, 1437-1450. [CrossRef] [PubMed]

46. Li, Y.; Pan, Y.; She, Q.; Chen, L. A novel carboxyl-terminal protease derived from Paenibacillus lautus CHN26 exhibiting high activities at multiple sites of substrates. BMC Biotechnol. 2013, 13, 89. [CrossRef] [PubMed]

47. Mothe, T.; Sultanpuram, V.R. Production, purification and characterization of a thermotolerant alkaline serine protease from a novel species Bacillus caseinilyticus. 3 Biotech 2016, 6, 53. [CrossRef] [PubMed] 
48. Rahman, R.N.Z.A.; Razak, C.N.; Ampon, K.; Basri, M.; Yunus, W.M.Z.; Salleh, A.B. Purification and characterization of a heat-stable alkaline protease from Bacillus stearothermophilus Fl. Appl. Microbiol. Biotechnol. 1994, 40, 822-827. [CrossRef]

49. Takami, H.; Akiba, T.; Horikoshi, K. Production of extremely thermostable alkaline protease from Bacillus sp. AH-101. Appl. Microbiol. Biotechnol. 1989, 30, 120-124. [CrossRef] 